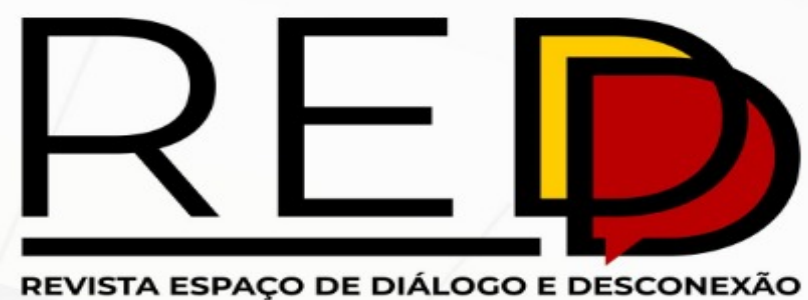

Link: https://periodicos.fclar.unesp.br/redd/index

\title{
A FUnÇão da PESQUisa Agrícola Na COLETIVIDAde CONTEMPORÂNEA
}

\author{
Jota Junior Marques Rosa ${ }^{1}$; Djane da Silva Ferreira ${ }^{2}$ \\ ID ORCID: ${ }^{1}$ https://orcid.org/0000-0002-6836-8691; ${ }^{2}$ https://orcid.org/0000-0003-0089-6479
}

Autor para correspondência e-mail: clubdojotinha2005@hotmail.com

Palavras-chave

Sociedade Atual

Faculdades Agrícolas

Papel

Universidade

\section{Keywords}

Current Society

Agricultural Colleges

Paper

University

\section{Palabras clave}

Sociedad Actual

Colegios Agrícolas

Papel

Universidad

\begin{abstract}
RESUMO
As mudanças na agricultura e a exigência de uma sociedade atual exigem certas adaptações na compreensão dos colégios agrícolas quanto ao papel que eles devem desempenhar. Isto é tanto mais verdade nos países que lutam por um desenvolvimento socioeconômico rápido. O documento discute primeiro os dois principais determinantes para o papel das faculdades agrícolas, ou seja, o papel da agricultura e o papel das universidades na sociedade atual. Os problemas de ensino são discutidos em três rubricas, a saber, prática versus formação teórica, treinamento amplo versus especialização. Formação com foco disciplinar versus formação profissional. A pesquisa em uma faculdade atual de agricultura é discutida nos capítulos sobre investigação básica versus investigação aplicada, pesquisa monodisciplinar versus pesquisa interdisciplinar, financiamento da investigação agrícola. Conclui-se que as faculdades de agricultura têm muitas possibilidades de aumentar a sua contribuição para o desenvolvimento socioeconômico.
\end{abstract}

\section{Abstract}

THE FUNCTION OF AGRICULTURAL RESEARCH IN CONTEMPORARY COLLECTIVITY

Changes in agriculture and the demand for a current society require certain adaptations in the understanding of agricultural colleges as to the role they should play. This is all the more true in countries striving for rapid socio-economic development. The paper first discusses the two main determinants of the role of agricultural colleges, namely the role of agriculture and the role of universities in today's society. Teaching problems are discussed under three headings, namely practical versus theoretical training, broad training versus specialization. Training with disciplinary focus versus vocational training. Research in a current faculty of agriculture is discussed in the chapters on basic versus applied research, monodisciplinary versus interdisciplinary research, funding for agricultural research. It is concluded that the faculties of agriculture have many possibilities to increase their contribution to socioeconomic development.

\section{RESUMEN}

LA FUNCIÓN DE LA INVESTIGACIÓN AGRÍCOLA EN LA COLECTIVIDAD CONTEMPORÁNEA Los cambios en la agricultura y la demanda de una sociedad actual requieren ciertas adaptaciones en la comprensión de los colegios agrícolas en cuanto al papel que deberían desempeñar. Esto es aún más cierto en los países que luchan por un rápido desarrollo socioeconómico. El documento primero discute los dos determinantes principales del papel de los colegios agrícolas, a saber, el papel de la agricultura y el papel de las universidades en la sociedad actual. Los problemas de enseñanza se discuten bajo tres encabezados, a saber, entrenamiento práctico versus entrenamiento teórico, entrenamiento amplio versus especialización. Entrenamiento con enfoque disciplinario versus entrenamiento vocacional. La investigación en una facultad de agricultura actual se discute en los capítulos sobre investigación básica versus investigación aplicada, investigación monodisciplinaria versus investigación interdisciplinaria, financiamiento para investigación agrícola. Se concluye que las facultades de agricultura tienen muchas posibilidades de aumentar su contribución al desarrollo socioeconómico.

${ }^{1}$ Governo do Estado de São Paulo.

${ }^{2}$ Governo do Estado de São Paulo. 


\section{INTRODUÇÃo}

Entre as instituições mais importantes no desenvolvimento revolucionário da agricultura nos últimos 50 anos estão às faculdades de agricultura. Como centro cerebral do progresso agrícola, eles forneceram com seus esforços de pesquisa a base de conhecimento científico, seu treinamento aumentou a qualidade do agente humano de produção e, em muitos casos, suas atividades de extensão trouxeram novos conhecimentos ao camponês.

Apesar de todas as contribuições feitas pelas faculdades agrícolas nos últimos tempos, há uma crescente discussão sobre o papel das faculdades de agricultura na sociedade atual que, até o momento, culminou na Conferência Mundial sobre Educação e Treinamento Agrícola, organizada pelas Nações Unidas. Em Copenhague e em suas reuniões de acompanhamento. Parece haver uma crescente conscientização de que as mudanças na agricultura e os requisitos de uma economia atual exigem certas adaptações no entendimento das faculdades agrícolas quanto ao papel que elas devem desempenhar.

A fim de reavaliar o papel das faculdades agrícolas na sociedade atual, primeiro elaboraremos os dois principais determinantes para o papel das faculdades agrícolas, ou seja, o papel da agricultura e o papel das universidades na sociedade atual. Nesta base, serão tiradas conclusões sobre as atividades de ensino e pesquisa das faculdades de agricultura necessárias para atender aos requisitos atuais.

A agricultura fornece a base de subsistência para a população através da produção de alimentos e matérias-primas. Tradicionalmente, os habitantes de cada país ou região dependiam da cesta de pão preenchida pelos agricultores, ou seja, todos dependiam da agricultura e estavam interessados em seu destino. Nos últimos tempos, o comércio regional e internacional reduziu a dependência da agricultura doméstica e a quantidade dos alimentos disponíveis é menos uma função da colheita do que da decisão política sobre a quantidade de importações de alimentos.

\section{O PAPEL DAS UNIVERSIDADES NA SOCIEDADE ATUAL}

As funções tradicionais das universidades são ensino e pesquisa. Em suas atividades de ensino, as universidades oferecem treinamento profissional para empregos de alto nível, bem como a educação necessária para o desenvolvimento da personalidade. A pesquisa universitária aumentou o corpo de conhecimentos teóricos e sua aplicação a problemas práticos (CHAUÍ, 2001)

A universidade tradicional se restringia principalmente a um círculo estreito de professores e estudantes dos estratos superiores da sociedade e vivia em relativo isolamento, "[...] a proverbial torre de marfim" (WAGNER, 2007, p. 148). Produzia a elite da nação, e a sociedade - por assim dizer - precisava A pesquisa era um privilégio dos professores, determinado em grande parte pelos interesses pessoais e seus contatos entre os entre si.

Todos sabem do brilhante desempenho desta universidade tradicional, que lançou as bases para o progresso da humanidade. Mas preocupada demais consigo mesma, essa universidade perdeu o contato com a sociedade até ficar completamente isolada e não entender as questões de seu entorno. Isso, no entanto, significou uma redução no desempenho: o critério final para medir o sucesso de uma universidade é a melhoria na vida das pessoas que ela serve. O benefício total de uma universidade só pode ser obtido se a universidade e a sociedade estiverem organicamente ligadas. De outro modo, as necessidades da sociedade devem estar no centro das atividades de uma universidade, e é necessário um ajuste flexível às mudanças nas necessidades, mas faltam - mais ou menos - em todo o mundo (CHAUÍ, 2001).

Universidades atuais foram desenvolvidas em uma época passada para satisfazer as necessidades da época. Nos países industrializados, a principal questão de hoje é abrir a universidade de elite às massas de jovens e ajustar-se à sociedade pluralista e democrática de hoje, e ao mesmo tempo manter o padrão de ensino e o nível de pesquisa. Nos países em desenvolvimento, as universidades foram construídas mais ou menos de acordo com modelos ocidentais e, às vezes, até como ramos de antigas instituições europeias.

No entanto, os assuntos e métodos da ciência correspondem à sociedade em que foram gerados: as universidades americanas e europeias atendem aos interesses das sociedades industriais americanas e europeias atuais ou anteriores. Os projetos e métodos de pesquisa estão centrados nos problemas, necessidades e condições ocidentais. Como consequência, universidades de todo o mundo enfrentam a mesma transição, de universidades para apenas alguns, para universidades para muitos. Mas, não se deve esquecer que as universidades dos países em desenvolvimento enfrentam responsabilidades adicionais (BOK, 2008).

Uma rápida melhoria no bem-estar da população requer a racionalização de todos os recursos disponíveis 
de uma nação. As universidades estão entre os mais importantes desses recursos. O desenvolvimento nacional é o resultado de dois processos simultâneos - crescimento e mudança, e ambos podem ser influenciados decisivamente pela ciência e tecnologia em todas as suas formas. Isso requer que uma universidade assuma a liderança nos esforços para o desenvolvimento e colocando as necessidades do processo de desenvolvimento no centro de suas atividades de ensino (BRESSER-PEREIRA, 2008).

Entre outros, isso significaria:

- Relacionar o treinamento em conteúdo, nível e número com a exigência do processo de desenvolvimento (CHAUÍ, 2001);

- Concentrar pesquisas sobre problemas relacionados à realidade do país e às necessidades do processo de desenvolvimento (BRESSER-PEREIRA, 2008);

- Transformar internacionalmente conhecimento disponível e torná-lo disponível e aplicável às condições locais (ZIZEK, 2015);

- Contribuir para a discussão de objetivos de desenvolvimento, seleção de meios e avaliação de realizações (ETZKOWITZ, 2009);

- Participar de uma comunicação animada entre universidade, público e políticos (ETZKOWITZ, 2009).

Ao cumprir os objetivos acima, a universidade deixaria sua torre de marfim e se tornaria um instrumento de desenvolvimento nacional política e recuperar seu significado social. Aqui estão certas condições prévias a serem cumpridas para transformar as universidades em um instrumento de mudança socioeconômica (WAGNER, 2007):

- A sociedade deve estar pronta para permitir que novos conhecimentos influenciem seus valores e objetivos (CHAUÍ, 2001);

- A sociedade deve permitir que as universidades participem do processo de formação de valores e estabelecimento de metas (GENTILI, 2001).

Desculpas será dizer que não é tarefa das universidades decidirem sobre valores e objetivos - isto é um campo de instituições políticas -, mas deve preparar a base material e intelectual para a decisão e contribuir para a discussão. Não é um problema para as universidades desempenhar um papel ativo no processo de desenvolvimento (CHRISTENSEN, 2002).

A universidade deve contribuir, discutir e até criticar, mas não deve entrar em uma situação de dependência. Uma antinomia entre liberdade e autodeterminação de a ciência e as demandas do governo e da sociedade pode surgir. Cada sociedade precisa encontrar sua fórmula para usar o conhecimento científico para orientar o processo de desenvolvimento e lucrar com a competência da universidade sem abrir mão da primazia das instituições políticas (MÉSZÁROS, 2001).

Uma sociedade só atingirá o valor total de sua universidade se a sociedade e a universidade estiverem ligadas e confrontarem as realidades de hoje e as necessidades de desenvolvimento do país. Isso requer uma transição da universidade tradicionalmente introspectiva para uma universidade que desempenha um papel ativo no processo de mudança na economia e na sociedade. O novo e muito mais amplo papel de uma atual faculdade de agricultura tem implicações para suas atividades de ensino e pesquisa (LUKÁCS, 2001).

\section{Agricultura ReQUer asSociações Profissionais}

Para atender às exigências da população cada vez maior, com seu maior poder de compra, e isso apesar de cada vez menos mão-de-obra por causa da alta emigração das áreas rurais, a agricultura aumentou seus produtos e produtividade, um processo que teve consequências para o preço de produtos agrícolas. Quanto mais pessoas moram nas cidades e precisam comprar alimentos no mercado, mais os preços agrícolas se tornam uma questão política. O interesse da sociedade urbana na agricultura é um interesse em preços baixos, e a solicitação do setor primário para aumentos de preços é um incômodo regular para a população urbana (MORRIS, 2001). 
O aumento da produção e produtividade da agricultura só poderia ser alcançado por divisão de trabalho e especialização. Hoje, apenas parte do processo de produção ocorre na fazenda, enquanto, além disso, a agricultura utiliza produtos industriais como fertilizantes, pesticidas, máquinas e equipamentos, os serviços do setor terciário, como bancos, seguros etc. e entrega seus produtos a outros setores de embalagem, processamento ou distribuição. Hoje a agricultura está profundamente entrelaçada com outros setores da economia. Ele não pode mais produzir sem seus insumos e serviços e atua como cliente desses outros setores, fornecendo trabalho e renda fora da agricultura (SANTOS, 2006).

Essas mudanças na agricultura tiveram consequências para a população agrícola. Muitas pessoas das áreas rurais migraram para as cidades e ocuparam as fileiras de trabalhadores no ensino médio e setores terciários. Para a população rural remanescente, a agricultura mudou de um modo de vida para uma profissão em que o conhecimento técnico desempenha um papel cada vez maior. Freqüentemente, a estrutura e organização da fazenda mudavam. Surgiram novas formas como a agricultura de meio período. Em áreas com propriedades muito pequenas e solo pobre, a migração rural-urbana atingiu o estágio, onde apenas os idosos vivem na vila. Particularmente nessas condições, a responsabilidade da agricultura pela preservação da natureza aumenta os papéis que desempenha hoje (MORRIS, 2001).

As mudanças na agricultura - resumidamente descritas aqui - trazem consigo novas tarefas de treinamento e pesquisa para faculdades de agricultura. O processo de produção agrícola tornou-se cada vez mais complexo e requer, portanto, ajuda científica em pesquisa e extensão. A necessidade de aperfeiçoar a alocação de insumos deu importância à economia agrícola, especialmente no campo do manejo agrícola. Mudanças necessárias na estrutura agrária requerem estudos especiais. A aplicação de insumos na agricultura criou novas tarefas em áreas como a Química e Engenharia Agrícola, e o processamento de alimentos tornou-se uma nova área de especialização. Tal organização altamente diferenciada da agricultura requer associações profissionais. Finalmente, a provisão de alimentos para a população com tantos colaboradores e grupos de interesse só pode ser alcançada com um sistema de marketing e distribuição em funcionamento, além de uma política agrícola sólida (DELGADO, 2001).

Para todas essas tarefas, as pessoas precisam ser treinadas e a pesquisa deve fornecer as informações científicas necessárias. As mudanças na agricultura ampliaram o papel das faculdades de agricultura como instituições de treinamento e pesquisa.

\section{ENSINAR EM UMA ATUAL FACULDAdE DE AGRICUltURA}

No passado, havia pouca discussão sobre os objetivos fundamentais do treinamento em faculdades agrícolas, e as mudanças na economia e na sociedade causavam apenas pequenos ajustes no conteúdo e nos métodos de treinamento. Os graduados das faculdades de agricultura de hoje trabalham em um amplo espectro de empregos (BALSADI, 2001).

Eles são agricultores e oficiais de extensão, silvicultores e horticultores, cientistas em laboratórios de pesquisa e funcionários de organizações profissionais, empresários e gerentes de indústrias agrícolas, tecnólogos de alimentos e funcionários do governo, gerentes de mercado e planejadores de desenvolvimento. A lista pode continuar por muito tempo (BALSADI, 2001).

Vale ressaltar que poucos graduados trabalham na agricultura, enquanto a maioria trabalha na agricultura e seus problemas e produtos. A maioria deles, de uma maneira ou de outra, está envolvida no planejamento e resolução de problemas ou na implementação de novas ideias e processos. Outro fator importante para a formação é o fato de que os requisitos do mercado de trabalho mudam simultaneamente com as mudanças na economia. Não sabemos quais serão os requisitos daqui a 25 anos, quando os graduados de hoje estiverem no auge de sua carreira. Os ajustes necessários no treinamento para atender aos novos requisitos exigem respostas para três áreas problemáticas (UZEDA, 2004).

Uma delas é a Prática versus treinamento teórico. Tradicionalmente, as universidades são tendenciosas em relação ao trabalho teórico, e sua aplicação aos problemas do mundo real é vista como científica e, às vezes, abaixo da dignidade de um cientista real. Por um lado, a teoria é à base do treinamento científico que Isso é fundamental para o desenvolvimento da ciência e da pesquisa. Não há nada mais prático do que uma boa teoria. Por outro lado, os problemas do cientista não são da sociedade e a situação do mundo real é geralmente diferente das suposições feitas. Em muitos modelos teóricos, portanto, embora o treinamento teórico seja 
fundamental no nível universitário, a aplicação de teorias para a resolução de problemas práticos deve ser ensinada e exercitada, se não apenas alguns cientistas, mas os graduados devem ser treinados para um amplo espectro de empregos (BULHÕES, 1990).

Outra é o amplo treinamento versus especialização. As primeiras faculdades de agricultura ofereceram amplo treinamento em agricultura geral para preparar agricultores e extensionistas para suas ocupações. Com as mudanças na agricultura e o crescente número e tipo de empregos, a tendência universal para a especialização profissional não excluiu as faculdades agrícolas, e hoje são facilmente oferecidos 8 ou 10, às vezes currículos bastante restritos. Até certo ponto, essa é uma consequência lógica da crescente diferenciação nos locais de trabalho e nos requisitos. A tecnologia alimentar e o melhoramento de plantas têm pouco em comum, e um economista agrícola dificilmente trabalhará em um laboratório de patologia de plantas. Um treinamento geral pode não realizar nada em muitos casos devido à profundidade insuficiente. Isso tem, no entanto, limitações (BALSADI, 2001).

A extrema especialização em nossos tempos exige certa introdução aos problemas da agricultura como um todo, para permitir que o graduado em seu papel de liderança entenda seu lugar e sua contribuição, para que a especialização não se transforme em uma mente estreita (CHAUÍ, 2001).

Além disso, o grau de especialização depende em parte do nível de desenvolvimento da agricultura. Parece que muitos países em desenvolvimento adotaram o modelo americano com especialização relativamente alta, sem levar em consideração os diferentes padrões de agricultura. Um agricultor com um diploma de bacharel em agricultura exige um especialista altamente treinado como seu conselheiro. Para os problemas gerais, ele próprio foi treinado (CLARK, 1998).

Um camponês pobre precisa de um consultor que entenda todas as facetas da fazenda e que possa ajudá-lo em todos os aspectos. Sob tais condições, um especialista corre o risco de obsolescência. Como conseqüência, cada país - e não cada faculdade - precisa, além do treinamento em áreas especializadas, de possibilidades de treinamento em agricultura geral para atender às necessidades dos futuros agricultores, gerentes agrícolas, extensionistas e outros (CLARK, 1998).

E em terceito, o treinamento com foco disciplinar versus treinamento profissional deve ser verificado. No passado, os professores transmitiam os seus conhecimentos aos seus alunos, ou seja, a universidade oferecia formação num determinado campo da ciência. O fato de que hoje um número de professores com campos diferentes ensinar em um currículo não trouxe uma mudança principal, porque o número crescente de professores muitas vezes reflete apenas a crescente divisão dos campos e especialização dos professores.

Em geral, a divisão das universidades em faculdades, e os currículos ensinados dentro de uma faculdade correspondem a campos e subcampos científicos. Desde que os graduados de tal currículo trabalhem depois como cientistas, em seu campo, nenhum dano é feito, mas essa é a exceção. Para a maioria, a formação nos domínios da ciência não satisfaz as exigências do emprego e existe um fosso entre a formação e o mercado de trabalho (CHAUÍ, 2001).

A maioria dos estudantes vai às universidades para se preparar para empregos de alto nível, não para comer da árvore da ciência. Os empregos exigem geralmente mais do que conhecimentos num domínio da ciência. Para muitos empregos, são necessários conhecimentos em dois domínios científicos, muitas vezes em duas faculdades. O proprietário de uma fábrica de processamento de alimentos, por exemplo, requer conhecimentos em processamento de alimentos e tecnologia de alimentos, bem como em gestão empresarial. O consultor de nutrição animal que trabalha para o serviço de extensão precisa de formação em ciências animais, bem como em métodos de extensão (BAUMAN, 2004).

O especialista em crédito cooperativo precisa de economia agrícola, bem como de conhecimentos financeiros e bancários e, talvez, de alguma formação em direito. Para a maioria dos empregos, o melhor candidato tem não só de ser formado num campo científico, mas tem de adquirir conhecimentos suficientes em pelo menos outro campo também. Este conhecimento adicional tende muitas vezes a ser uma gestão de um tipo ou de outro na modernidade, agora líquida (BAUMAN, 2004).

Como o cumprimento dos requisitos do trabalho não é apenas necessário para a fácil colocação dos estudantes, mas para dar a melhor contribuição possível para o desenvolvimento da economia, a faculdade atual precisa de flexibilidade nos seus currículos para que o estudante tenha a oportunidade de alargar a sua formação para além dos limites de um único campo da ciência ou departamento (CLARK, 1998). 
A variedade de interesses e circunstâncias pessoais, as peculiaridades do atual mercado de trabalho e a dificuldade de prever o futuro mercado de trabalho tornam difícil decidir sobre a mistura de disciplinas mais adequada. Nesta situação, a decisão é mais bem colocada nas mãos de quem tem de assumir o risco, o aluno, desde que sejam tomadas medidas de salvaguarda para evitar a escolha do caminho mais fácil e os alunos recebem aconselhamento adequado (CHAUÍ, 2001).

Resumindo, parece que para as três áreas problemáticas, ou seja, formação orientada para a prática versus teoria, formação alargada versus especialização e foco disciplinar versus formação profissional, não existe uma resposta definitiva para uma ou outra escolha. Em cada caso, ambos são necessários, dependendo dos planos de carreira futura. A atual faculdade de agricultura, portanto, requer grande flexibilidade em seus requisitos curriculares para que os estudantes tenham certa escolha correspondente aos seus interesses pessoais acima $\mathrm{e}$ além de certos cursos obrigatórios (CLARK, 1998).

A formação dos estudantes para satisfazer as exigências dos nossos tempos exige um ajustamento não só no conteúdo, mas também no método de formação. A aula tradicional é inevitável porque é o meio que mais economiza tempo para ensinar os fundamentos do campo. Portanto, eles têm o seu lugar, especialmente em cursos introdutórios. No entanto, eles precisam de formas complementares de instrução por causa de suas limitações (CLARK, 1998).

A aula clássica tende a induzir a memorizar, repetir e copiar. O graduado universitário de nosso tempo, no entanto, deve ser capaz de pensar criticamente. Ele deveria questionar os chamados fatos. Queremos que ele seja treinado no uso criativo da ciência para atingir objetivos, não apenas na memorização dos princípios (CLARK, 1998).

A maioria dos trabalhos exigem resolução diária de problemas que surgem, e a solução muitas vezes reside na combinação de diferentes pedaços de conhecimento. Para treinar os alunos para estes requisitos, outros métodos de ensino do que palestras são necessários. Exercícios, em que os alunos tentam encontrar respostas para problemas dados, são um exemplo. Artigos curtos sobre temas específicos podem ser benéficos e dar exercício num dos requisitos do dia-a-dia da vida profissional: compilar e escrever um artigo de uma forma precisa, abrangente e curta. Trazer os alunos para as aldeias e para as fábricas significa ensinar e trabalhar no mundo real, onde os problemas não são isolados como em experiências de laboratório, mas aspectos práticos como a disponibilidade de mão-de-obra, custos e tempo desempenham muitas vezes um papel decisivo na determinação da solução na modernidade líquida (BAUMAN, 2004).

A vida profissional, devido à complexidade dos problemas, as soluções são frequentemente o resultado da cooperação de uma equipa de especialistas, da qual todos contribuem com o seu conhecimento particular. Embora esse trabalho interdisciplinar tenha sido discutido muito frequentemente nos últimos anos, a formação dos alunos durante a maioria dos anos de formação enfatiza apenas o trabalho individual e realização. Pode valer à pena considerar o valor de tópicos abrangentes a serem tratados por um grupo de alunos. Enquanto cada um lida com um aspecto limitado de acordo com seus campos, ele reconhece sua contribuição como parte de toda a tarefa e aprende a apreciar as limitações do campo individual para resolver problemas práticos (BAUMAN, 2004).

A universidade como instrumento de desenvolvimento socioeconômico não pode limitar as suas atividades de formação aos estudantes propriamente ditos. A melhoria no nível de ensino sobre o passado faz com que os graduados de hoje muito mais qualificados do que os anteriores. Isto exige a requalificação dos ex-alunos, a fim de dotar a economia da mão-de-obra necessária ao nível exigido. Além disso, as ciências estão se desenvolvendo tão rapidamente hoje que a aprendizagem não pode terminar no dia da formatura. Que outra instituição que não a universidade está na posição de dar formação em serviço no nível universitário, uma necessidade urgente em uma economia expandindo seu escopo e produtividade (MÉSZÁROS, 2001).

Finalmente, há numerosas pessoas desempenhando papéis de liderança no processo de desenvolvimento da nação que se beneficiariam de cursos de curta duração e fazer depois um trabalho melhor para a sociedade. Escusado será dizer que o benefício é mútuo. Treinar não só os estudantes, mas também os adultos que estão no meio de sua carreira e têm excelentes experiências, dá as impressões da universidade quanto aonde dói o sapato e como os problemas olham para os olhos de um agricultor ou um engenheiro. Ele garante que o pensamento na universidade se desenvolve paralelamente às necessidades e desejos da sociedade e, assim, melhora o significado social das atividades de ensino (MÉSZÁROS, 2001). 
Um comentário final sobre o ensino: faz parte do papel das faculdades agrícolas ensinar outras faculdades, o que é a agricultura atual e qual o seu papel na sociedade. Quanto menos pessoas estiverem envolvidas na agricultura, mais importante é que as personalidades líderes de todas as profissões tenham uma compreensão básica dos problemas e condições deste sector cada vez mais reduzido da economia e da sociedade.

\section{Pesquisa em uma faculdade atual de agricultura}

A investigação é, por definição, um trabalho criativo realizado de forma sistemática para aumentar o acervo de conhecimentos científicos e tecnológicos e para utilizar o acervo de conhecimentos na concepção de novas aplicações. É isto que faz de uma instituição de ensino superior uma universidade. É indispensável para que o ensino permaneça vivo e inspirador. Só a possibilidade de realizar investigação atrairá professores de alto nível, e a investigação dá à universidade reconhecimento e reputação internacional.

Uma questão fundamental para a faculdade atual de agricultura é: que tipo de pesquisa deve ser realizada e quem determina os objetivos das atividades de pesquisa? Internacionalmente, existe uma tradição de liberdade acadêmica que inclui a liberdade de investigação. O pesquisador define os temas de seu trabalho de pesquisa e tende a resistir à intervenção de superiores ou colegas. Ele quer selecionar um tema que satisfaça sua curiosidade e que acredite ser importante, cientificamente gratificante e, portanto, que promova suas carreiras. Indiscutível, a maioria dos resultados de pesquisa original saiu deste sistema, e muitos problemas urgentes foram resolvidos porque certo pesquisador tomou-a e passou anos de esforços para encontrar uma solução (BOK, 2008).

Hoje, no entanto, certos fatores em todo o mundo causam dúvidas neste sistema de liberdade quase ilimitada na pesquisa:

- Os custos crescentes da investigação tornam possível uma política de laissez-faire em relação à questão da investigação (AGUIAR, 2015);

- Hoje, na maioria dos países, não temos uma ou duas universidades com um número limitado de professores, mas um sistema expandido de aprendizagem acadêmica com um grande corpo docente científico (CHAUÍ. 2001);

- Tendo em conta a complexidade dos problemas atuais, a extrema diversidade da investigação universitária tem geralmente pouco impacto (CHRISTENSEN, 2002);

- Os planos nacionais de desenvolvimento estabeleçam uma determinada ordem de prioridade nos tópicos de investigação que podem não corresponder aos interesses individuais da investigação (BRESSER-PEREIRA, 2008);

Quanto maiores forem os fundos de investigação envolvidos, quanto maior for à mão-de-obra dedicada à investigação e quanto mais urgentes forem às necessidades de desenvolvimento, mais importante será uma política de investigação com uma formulação sólida dos objetivos, meios para definir prioridades e métodos fiáveis de avaliação. A principal consideração dessa política de investigação é a investigação em benefício do público e não em benefício do investigador. Numa escola atual de agricultura, as atividades de investigação têm de ser reorientadas para satisfazer as necessidades de desenvolvimento (BRESSER-PEREIRA, 2008).

Isto não acontecerá sem causar fricção. Primeiro, pode haver um conflito entre objetivos de pesquisa, determinados por requisitos de desenvolvimento, e interesses na promoção do conhecimento científico. Em segundo lugar, tanto a universidade como o pesquisador estão envolvidos na competição internacional por sua reputação. Se estiverem interessados em obter reconhecimento internacional, devem recorrer a Harvard e Oxford para obter exemplos de programas e objetivos de investigação (CLARK, 1998).

Quanto mais o fizerem, menos contribuirão provavelmente para o desenvolvimento do seu país, porque as questões relevantes são diferentes. As universidades têm de encontrar uma saída para as dificuldades decorrentes da sua dupla composição. Por um lado, fazem parte da comunidade nacional que as apoia, por outro lado, fazem parte da comunidade científica internacional que não só influencia a vida intelectual como a torna possível (BOK, 2008).

Há três aspectos da pesquisa na faculdade atual de agricultura que requerem alguma discussão. Pesquisa 
básica versus aplicada, por exemplo. As faculdades de agricultura, por causa de seus assuntos, são instituições de pesquisa aplicada. Afinal, a agricultura é a aplicação da ciência ao processo de produção de alimentos e matériasprimas. Além disso, dentro do processo de desenvolvimento agrícola, o colégio agrícola tem a tarefa de adotar o conhecimento existente para as condições e necessidades particulares do país e para as diferenças regionais. Essa transferência do conhecimento teórico existente para aplicação prática é possível apenas dentro do próprio país, enquanto a pesquisa básica pode, em princípio, ser realizada em qualquer lugar do mundo (BOK, 2008).

O conhecimento científico básico é transferível, enquanto a aplicação da ciência aos problemas do mundo real tende a não ser devido às diferenças no ambiente econômico, político e cultural natural. Portanto, a pesquisa teórica é menos importante nos países, dando grande importância à aceleração do processo de desenvolvimento. Existe o perigo de muita ênfase ser colocada na pesquisa básica e pouco trabalho gasto em problemas imediatos (BAUMAN, 2004).

Pesquisadores de todo o mundo acham que a pesquisa básica leva a uma posição profissional mais elevada do que o engajamento na pesquisa aplicada, e muitas vezes as mentes mais criativas e imaginativas passaram para a área de construção de ferramentas em vez de solução de problemas. Certamente, não há uma linha divisória clara entre pesquisa básica e aplicada, e a pesquisa básica poderá apresentar resultados muito práticos amanhã. A personalidade do pesquisador também desempenha um papel. Portanto, as faculdades agrícolas devem ter sua ciência pura, mas a ciência pura não deve monopolizar a pesquisa. Em geral, os tópicos de pesquisa aplicada atendem em maior medida aos requisitos imediatamente relevantes da sociedade (BOK, 2008).

Pesquisa monodisciplinar versus interdisciplinar, evidencia que a experiência mostrou, particularmente na agricultura, os maiores ganhos não advêm de uma melhoria em um único processo, mas da interação de uma combinação adequada de práticas aprimoradas e que esforços fragmentados de pesquisa geralmente se mostram ineficazes e dispendiosos (AGUIAR, 2015).

A enorme interação de fatores dentro dos sistemas agrícolas torna a pesquisa agrícola aplicada especialmente adequada para uma abordagem abrangente de várias disciplinas, tanto no diagnóstico de problemas quanto na solução de problemas. Soluções monodisciplinares de problemas práticos podem facilmente ser impraticáveis no nível da fazenda (AGUIAR, 2015).

Certamente, nem todo e qualquer problema requer uma abordagem interdisciplinar e, muitas vezes, após um diagnóstico conjunto, as ciências individuais precisam primeiro fazer a lição de casa, mas depois é necessária uma integração da contribuição do assunto, se a pesquisa em laboratório deve ser aplicável no nível da fazenda (SANTOS, 2006).

Apesar dessa situação, o crescente conhecimento científico leva à fragmentação e especialização e, durante muito tempo, criou fronteiras quase intransponíveis entre disciplinas e departamentos. Se uma faculdade de agricultura quer contribuir para resolver os problemas da população agrícola, precisa encontrar maneiras e meios que tornem a cooperação entre departamentos e assuntos normais e sem necessidade de acordos especiais.

$\mathrm{O}$ futuro da investigação e, portanto, a escala em que um colégio de agricultura pode contribuir para $\mathrm{o}$ desenvolvimento da agricultura, depende da quantidade de recursos financeiros. A pesquisa é cara, e quanto mais sofisticados forem os projetos de pesquisa, maiores serão os custos, especialmente nos campos científicos. Isto cria um problema financeiro em todo o mundo, especialmente para as universidades privadas, que não podem contar facilmente com o orçamento do governo. As universidades geralmente enfrentam esses problemas quando se desenvolvem desde a graduação até o nível de pós-graduação. Com a introdução do treinamento de pós-graduação, a pesquisa não é mais um hobby do professor, mas uma parte integrante das atividades da universidade, porque o treinamento de pós-graduação é treinamento em, e por, pesquisa (SANTOS, 2006).

Os governos e as instituições governamentais terão, em parte, que intervir e contribuir para os fundos de pesquisa, talvez por meio de contratos especiais por meio dos quais eles utilizam os recursos de equipamentos e expertise para fazer parte de suas necessidades de pesquisa (ETZKOWITZ, 2009).

Tendo em vista o volume das necessidades de investigação e as limitações de recursos, deveria ser possível um tipo de cooperação entre governos e universidades que dê aos governos o controlo necessário sobre a utilização dos seus fundos e às universidades a liberdade necessária no âmbito de um quadro de trabalho acordado no contrato de investigação (ETZKOWITZ, 2009).

Os governos não são os únicos contratantes de investigação possíveis. Numerosas pequenas e médias in- 
dústrias alimentares e agroindustriais não podem pagar um departamento de investigação como as grandes empresas, mas requerem investigação para melhorar os seus produtos, processos de produção, controlos de qualidade, etc. Aqui, as formas e meios de cooperação têm de ser desenvolvidos para benefício mútuo (ETZKOWITZ, 2009).

Se, por exemplo, os estudantes de pós-graduação assumem essas tarefas com a orientação de seus professores e pagamento das indústrias, não são apenas as bolsas de estudo para os estudantes de pós-graduação e os custos de pesquisa para suas teses cuidadas. Esta pesquisa, por necessidade, está relacionada com problemas práticos e o estudante é introduzido aos problemas de seu possível local de trabalho futuro. Mais uma vez, os problemas de independência e ética em pesquisa têm de ser resolvidos, mas tais acordos podem ajudar a financiar a pesquisa, enquanto essa pesquisa é, ao mesmo tempo, uma contribuição para o desenvolvimento econômico (ETZKOWITZ, 2009).

Os custos da investigação podem variar muito, consoante a forma como é conduzida. Sempre que possível, as casas venílicas, por exemplo, são mais baratas do que as casas verdes. Para as faculdades de agricultura, muitos objetos de investigação requerem campos para experiências, testes de cultivo, etc. Em vez de comprar terras caras para fazendas universitárias, organizar experiências nas aldeias nos campos dos camponeses é muito mais barato, mesmo quando os camponeses recebem compensação. Ao mesmo tempo, as experiências estão mais relacionadas com o mundo real. Mas, tais arranjos não são viáveis para todos os tipos de pesquisa (CLARK, 1998).

A questão da contribuição de uma faculdade atual de agricultura para as necessidades da sociedade não é completamente tratada sem alguns comentários sobre a extensão dos resultados do trabalho de pesquisa. Enquanto nos países industrializados uma infraestrutura altamente desenvolvida liga as universidades a outras instituições públicas e privadas garante a disseminação imediata de novos conhecimentos e resultados de pesquisa, este tipo de infraestrutura não existe nos países em desenvolvimento, pelo menos não na medida do necessário (ETZKOWITZ, 2009).

Portanto, a universidade não se transforma prontamente em um agente de desenvolvimento socioeconômico e medidas especiais são necessárias. Um espectro de possibilidades como publicações, professores públicos, cursos de formação, artigos de jornal, etc. estão disponíveis para assegurar que os resultados das universidades sejam transmitidos à sociedade o mais rápido possível.

\section{Conclusão}

O texto em questão tentou desenvolver o papel das faculdades agrícolas na sociedade atual e discutir algumas possibilidades em atividades de ensino e pesquisa, através das quais elas poderiam aumentar sua contribuição para o desenvolvimento socioeconômico. Nem todos os pontos que foram discutidos são viáveis em todos os casos, embora existam certamente muitas outras possibilidades. Em todo o caso, existem grandes oportunidades para que as faculdades agrícolas aumentem a sua importância para a sociedade em geral e desempenhem um papel ativo no desenvolvimento da nação. Grandes oportunidades são uma grande responsabilidade.

\section{REFERÊNCIAS}

AGUIAR, L. As relações da tríplice hélice nas fundações de apoio brasileiras: uma avaliação da dinâmica de cooptação de recursos em projetos de inovação. 2015. 154 f. Dissertação (Mestrado em Engenharia de Produção). Universidade Federal do Rio Grande do Norte, Natal/RN, Abr. 2015.

BALSADI, O. V. Mudanças no meio rural e desafios para o desenvolvimento sustentável. Revista São Paulo em Perspectiva, São Paulo/SP, v. 15, n. 1, p. 155-165, Jan. 2001.

BAUMAN, Z. Medo Liquido. Rio de Janeiro, RJ: Jorge Zahar, 2004.

BOK, D. Más allá de la torre de marfil: la responsabilidad social de la universidad moderna. Buenos Aires: Universidad de Palermo - UP, 2008. 
BRESSER-PEREIRA, L. C. Nação, câmbio e desenvolvimento. Rio de Janeiro, RJ: FGV Editora, 2008. BULHÕES, A. Elogio da corrupção. São Paulo, SP: Edições Sicilliano, 1990.

CHAUÍ, M. Escritos sobre a universidade. São Paulo: Editora UNESP, 2001.

CHRISTENSEN, C. M. The innovator's dilemma: the revolutionary book that will change the way you do business. New York: Collins, 2002.

CLARK, B. R. Creating entrepreneurial universities: organizational pathways of transformation. Oxford: Pergamon-Elsevier Science, 1998.

DELGADO, N. Política econômica, ajuste externo e agricultura. In: LEITE, S. (org.), Políticas públicas e agricultura no Brasil. 2 ed. Porto Alegre, RS: Editora da UFRGS, 2001.

ETZKOWITZ, H. Hélice tríplice: Universidade-Indústria-Governo, Inovação em Movimento. Porto Alegre, RS: Edipucrs, 2009.

GENTILI, P. (org.) Universidade na penumbra: neoliberalismo e reestruturação universitária. São Paulo, SP: Cortez, 2001.

LUKÁCS, G (org.). Sociologia. São Paulo, SP: Ática, 1981.

MÉSZÁROS, I. A educação para além do capital. 2 ed. São Paulo, SP: Boitempo, 2006.

MORRIS, D. O macaco nu: um estudo do animal humano. São Paulo, SP: Record, 2001.

PEREIRA, S. Políticas Públicas e Agricultura no Brasil. Porto Alegre, RS: Ed. UFRGS, 2001.

SANTOS, M. A natureza do espaço: técnica e tempo, razão e emoção. 4 ed. 2 reimpr. São Paulo, SP: EDUSP, 2006.

UZEDA, M. O desafio da agricultura sustentável: alternativas viáveis para o Sul da Bahia. Florianópolis, SC: UESC, 2004.

WAGNER, E. Hannah arendt: ética e política. São Paulo, SP: Ateliê Editorial, 2007.

ŽIŽEK, S. Em defesa das causas perdidas. São Paulo, SP: Boitempo, 2015. 